\title{
A INDISSOCIABILIDADE CONSCIENTE: UMA REFLEXÃO SOBRE O COTIDIANO DA DOCÊNCIA
}

\author{
Conscious inseparability: a reflection on the daily life of teaching
}

\author{
Marilene Reimer ${ }^{1}$ \\ Rosa Maria Zagonel ${ }^{2}$
}

\begin{abstract}
RESUMO
A indissociabilidade ensino-pesquisa-extensão, no dia-a-dia das universidades, é uma construção contínua, que se confunde com a discussão sobre a missão da universidade no século XXI. Da mesma forma, a extensão universitária está cotidianamente articulada com o conhecimento e muitas são as concepções adotadas nas instituições. O presente artigo propõe uma reflexão sobre o papel da indissociabilidade na extensão e na formação integral do estudante universitário por meio da análise do perfil dos atores envolvidos no ensino, pesquisa e extensão, das ações realizadas e dos conhecimentos construídos. A discussão parte da nossa experiência no acompanhamento de Programas e Projetos de Extensão na UFPR e se fundamenta em autores como Freire, Boaventura Santos e Morin.
\end{abstract}

Palavras-chave: indissociabilidade; interação dialógica; extensão universitária; diversidade.

\begin{abstract}
The inseparability of teaching, research and extension in the daily life of universities is an ongoing construction that is confused with the discussion concerning the mission of universities in the twenty-first century. Likewise, university extension in daily life is articulated with knowledge, and there are many concepts adopted by different institutions. This article aims to reflect on the role of inseparability in the extension and integral preparation of university students by analyzing the profile of the actors involved in teaching, research and extension of actions that are taken and the knowledge that is constructed. The discussion is based on our experience in monitoring extension programs and projects at UFPR and is founded on the works of authors such as Freire, Boaventura Santos and Morin.
\end{abstract}

Keywords: inseparability; dialogic interaction; university extension; diversity.

\footnotetext{
1 Graduada em Pedagogia pela UFPR, pedagoga da Universidade Federal do Paraná, Praça Santos Andrade, 50, térreo, CEP 80.020.300, Curitiba, Paraná, telefone (41) 3310-2712, email: marilener@ufpr.br.

2 Mestre em Tecnologia pela UTFPR, pedagoga da Universidade Federal do Paraná, Rua General Carneiro, 460, 2ํandar, CEP 80060-150, telefone (41) 3360-5139, email: rmzagonel@ufpr.br.
}

REIMER, Marilene e ZAGONEL, Rosa M. A indissociabilidade consciente: uma reflexão sobre o cotidiano da docência. Extensão em Foco, Curitiba: Editora da UFPR, nr.9, jan/jun 2014, p.50-60. ISSN 2358-7180 


\section{INTRODUÇÃO}

Este artigo pretende levar o leitor a uma reflexão sobre a conscientização necessária aos educadores universitários a respeito da indissociabilidade do ensino, da pesquisa e da extensão nas atividades extensionistas e de formação dos estudantes.

Trabalhamos durante alguns anos na Coordenadoria de Extensão da UFPR, diretamente envolvidas na orientação, análise e acompanhamento de Programas e Projetos de Extensão. Este contato próximo com docentes, técnicos e alunos extensionistas permitiu a visualização da indissociabilidade ensino-pesquisa-extensão em suas múltiplas formas e configurações e seu impacto sobre a prática docente, na formação do estudante e na relação com os participantes externos.

Percebemos que no interior da estrutura física e administrativa, construída pela universidade para que as ações tenham um caráter legal, é muitas vezes difícil enxergá-las como algo único e construído articuladamente. $\mathrm{Na}$ prática da instituição se fala nas ações de ensino, pesquisa e extensão de forma que elas pareçam recortadas ou fragmentadas, em virtude da burocracia institucional. No entanto, quando se discutem as problemáticas da sociedade em termos de conhecimento, sejam eles teóricos e/ou práticos, percebe-se que uma ação não existe sem a outra, pois embora diferentes ou até mesmo opostas, elas se complementam, se interconectam e interdependem. Não podemos afirmar que elas não existam em separado, mas entendemos que a essência de cada uma é indissociada das outras.

O caminho para a reflexão passa pela análise do perfil dos atores destas ações, sua visão de mundo e visão do outro, além da relação que cada um estabelece com a instituição e os sujeitos participantes destas ações. Para fundamentar a discussão lançamos mão de autores como Paulo Freire, Boaventura Santos e Edgar Morin.

\section{PERCURSO HISTÓRICO}

REIMER, Marilene e ZAGONEL, Rosa M. A indissociabilidade consciente: uma reflexão sobre o cotidiano da docência. Extensão em Foco, Curitiba: Editora da UFPR, nr.9, jan/jun 2014, p.50-60. ISSN 2358-7180 
As questões envolvendo a indissociabilidade ensino-pesquisa-extensão foram construídas ao longo da trajetória da extensão no Brasil. As primeiras ações ocorreram no início do século XX por meio de cursos e conferências abertos ao público, tratando de temas distantes da vida e das questões reais. Esta concepção foi ampliada pelo Estatuto da Universidade Brasileira de 1931, em que a extensão passou a ter o objetivo de difundir conhecimentos e informações e, com isso, conformar a população aos interesses do governo. Entretanto, o contato direto dos estudantes com a realidade social instigou reflexões e discussões que levaram as universidades e os gestores públicos a construir e reconstruir os conceitos e as práticas de extensão universitária.

$\mathrm{Na}$ década de 1960 houve avanços significativos tanto na concepção como na atuação extensionista. As ações de conscientização por meio da educação, conduzidas por Paulo Freire, encontraram grande repercussão nos meios estudantis e foram adotadas como instrumento de transformação da sociedade. A Ditadura Militar rompeu com este movimento e as atividades extensionistas foram redirecionadas, passando a ter uma característica assistencial; um período em que a ação transformadora da extensão universitária foi podada e o conhecimento produzido pela universidade se distanciou da população.

A partir da década de 1980, com a abertura política e a gradual volta à democracia, intensificou-se o debate sobre a extensão e sua indissociabilidade com o ensino e a pesquisa. Em 1987 foi criado o Fórum Nacional de PróReitores de Extensão das Universidades Públicas Brasileiras - FORPROEX, com o objetivo de ser um órgão próprio para o debate, a organização e a definição do papel da extensão na universidade. O Fórum definiu a extensão como um "processo educativo, cultural e científico que articula o ensino e a pesquisa de forma indissociável e viabiliza a relação transformadora entre a universidade e a sociedade." (NOGUEIRA, 2000, p. 11). O princípio da indissociabilidade foi incorporado à Constituição Federal de 1988, (art. 207) e à Lei de Diretrizes e Bases da Educação Nacional, Lei №. 9394 de 1996 (art. 43), mas sem definição da sua concepção e prática na universidade. A discussão sobre a identidade e a função da extensão universitária e da indissociabilidade,

REIMER, Marilene e ZAGONEL, Rosa M. A indissociabilidade consciente: uma reflexão sobre o cotidiano da docência. Extensão em Foco, Curitiba: Editora da UFPR, nr.9, jan/jun 2014, p.50-60. ISSN 2358-7180 
suas possibilidades e seus limites, está imersa em uma discussão maior sobre a identidade da própria universidade e sua missão no mundo atual.

O Fórum vê a universidade "como espaço acadêmico onde se exercitem teorias e práticas transformadoras da Sociedade e do Estado [...] uma universidade capaz de expressar multiplicidade de pensamentos, às vezes conflitantes" (FORPROEX, 2006, p. 41). Entendemos que os conhecimentos presentes no espaço acadêmico estão recortados em disciplinas e metodologias específicas, mas ao mesmo tempo inseridos em um todo maior. Esta relação existente entre o recorte e o todo possibilita a "estruturação dos problemas sociais e do desenvolvimento regional e local" (p. 41) em uma perspectiva sistêmica e interdisciplinar. Para isto são necessários

\begin{abstract}
educadores afeitos à investigação e aos questionamentos quanto aos rumos da sociedade, que adotam e criam novas práticas pedagógicas, uma nova organização curricular permeável às transformações em curso, interdisciplinar, privilegiando a articulação teoria-prática na formação integral do estudante e [...] uma nova perspectiva curricular na qual é inevitável a indissociabilidade ensino/pesquisa/extensão enquanto eixo de formação do estudante [...] (FORPROEX, 2006, p. 43-44).
\end{abstract}

As discussões sobre este tema também tem e tiveram relevância nos Congressos Ibero-Americanos de Extensão Universitária, evidenciando a importância fundamental da indissociabilidade nos debates extensionistas internacionais. Em 2007, na Colômbia, Robayo afirmou que "refletir sobre o sentido contemporâneo da extensão implica em observar que a Universidade só irá encontrar seu lugar social de agente transformador da sociedade se cada um dos pilares pesquisa-ensino-extensão estiverem equilibrados e indissociavelmente articulados" (ROBAYO, 2007).

\title{
A INDISSOCIABILIDADE NA DIVERSIDADE
}

A indissociabilidade ensino-pesquisa-extensão pressupõe um pensar nas ações acadêmicas de forma sistêmica, isto é, articular debates e discussões entre as diversas esferas da instituição, possibilitando efetivar na prática essa relação com visibilidade nos três âmbitos. As atividades de ensino, pesquisa e extensão, adotando como referência os projetos pedagógicos dos cursos e em consonância com os mesmos, devem envolver de forma criteriosa

REIMER, Marilene e ZAGONEL, Rosa M. A indissociabilidade consciente: uma reflexão sobre o cotidiano da docência. Extensão em Foco, Curitiba: Editora da UFPR, nr.9, jan/jun 2014, p.50-60. ISSN 2358-7180 
a perspectiva técnico-profissional e a formação política e cidadã dos estudantes. Nesse foco, a razão de ser de cada ação deveria ter a indissociabilidade - na perspectiva da formação acadêmica baseada em um currículo flexibilizado - como objeto ou instrumento de construção do conhecimento, caracterizando as possibilidades de atuação.

O ensino, a pesquisa e a extensão têm características e olhares próprios sendo imprescindível a presença de cada um deles - como diferentes facetas de um prisma ${ }^{3}$ - para a visualização e compreensão integral do conhecimento. Os princípios (interdisciplinaridade ${ }^{4}$, interação dialógica, impacto, entre outros), ocultos dentro da luz branca que incide no prisma, são revelados em toda a sua riqueza e diversidade ao serem decompostos pelas facetas ensinopesquisa-extensão. Assim, para a formação integral do estudante, todas as ações da Universidade devem passar pelos três componentes do prisma, que são indissociáveis.

A estrutura da universidade, muitas vezes, cria a imagem de um docente em disciplinas específicas, ou participando de projetos de pesquisa e extensão sem interlocução com outros atores e conhecimentos. Tanto o professor em sala de aula como o coordenador de pesquisa ou extensão, aparentemente isolados na sua ação e na sua visão de mundo, não devem perder a perspectiva da indissociabilidade e do pertencimento ao todo. Eles são parte do prisma e não existiriam sem o todo, da mesma forma que o todo necessita deles para se constituir.

Em vista disso a "extensão equilibrada e a indissociabilidade articulada" (ROBAYO, 2007) não poderiam ser realizadas por todos, porque há muitos olhares sobre o real e muitas práticas diferenciadas nas relações com o outro. Além disso, em qualquer das ações, deve-se respeitar a escolha de ferramentas e instrumentos de cada educador para o exercício da docência. Ou, nas palavras de Paulo Freire:

\footnotetext{
${ }^{3}$ A luz solar (branca), ao ser decomposta em um prisma, possibilita a visualização de espectros de várias cores, como no arco-íris.

${ }^{4} \mathrm{~A}$ interdisciplinaridade é entendida neste contexto como a interação de diferentes disciplinas, áreas de conhecimento, metodologias e sujeitos.
}

REIMER, Marilene e ZAGONEL, Rosa M. A indissociabilidade consciente: uma reflexão sobre o cotidiano da docência. Extensão em Foco, Curitiba: Editora da UFPR, nr.9, jan/jun 2014, p.50-60. ISSN 2358-7180 
é não só interessante mas profundamente importante que os estudantes percebam as diferenças dos fatos, as posições às vezes antagônicas entre professores na apreciação dos problemas e no equacionamento de soluções. Mas é fundamental que percebam o respeito e a lealdade com que um professor analisa e critica as posturas dos outros. (FREIRE, 2002, p. 10).

É relevante considerar a diversidade de atores envolvidos no ensino, na pesquisa e na extensão, cada um com seu perfil próprio de atuação profissional e acadêmica. A forma como os diversos sujeitos veem e praticam a indissociabilidade está intimamente ligada a sua trajetória pessoal e acadêmica e pode ser, também, influenciada pela área de conhecimento em que atuam. Além disso, essa diversidade é construída pelas relações que se estabelecem nas práticas acadêmicas.

Alguns focam em responder perguntas com metodologia, parâmetros definidos, prazos determinados, frutos da pesquisa científica como acontece, por exemplo, nas áreas de Ciências Exatas ou Tecnológicas. As ações de ensino e extensão decorrentes destas pesquisas podem ser cursos ou projetos com objetivos fechados, com pouca participação no planejamento e execução por parte do público-alvo. No entanto, ações neste formato são imprescindíveis para a Ciência e fundamentam outras ações que envolvem a interação com os participantes.

Outros buscam os meandros das discussões, dos diálogos abertos, da teorização, do aprofundamento, da interiorização dos conceitos, frutos do ensino, inclusive o compartilhado, com troca, com articulação. Ações desta natureza podem ser embasadas na pesquisa-ação e/ou participativa e aparecem com mais frequência nas Ciências Humanas e na Educação, embora existam ações de extensão de outras áreas como a da Saúde, por exemplo, que também atuam neste formato. Essa busca coletiva de resolução para um problema de grupo, quando em parceria, tem no diálogo a base do crescimento e da democracia, como princípios de autonomia e autogestão.

O autor Boaventura Santos fala desta abertura para o diálogo, para o conhecimento existente fora da universidade:

A Ecologia dos Saberes é a extensão ao contrário. É a universidade preparar-se para a ideia de que as práticas sociais, mesmo quando são

REIMER, Marilene e ZAGONEL, Rosa M. A indissociabilidade consciente: uma reflexão sobre o cotidiano da docência. Extensão em Foco, Curitiba: Editora da UFPR, nr.9, jan/jun 2014, p.50-60. ISSN 2358-7180 
informadas pelo conhecimento científico, possuem um conhecimento que é único. Isto é, o conhecimento científico tem que saber dialogar com outros conhecimentos - porque nas práticas sociais outros conhecimentos estão presentes - e trazê-los para dentro da universidade. $O$ que significa eventualmente os alunos universitários terem contato com líderes comunitários que hoje não são cientificados para ensinar na universidade, mas provavelmente devem vir à universidade para dar sua experiência. (SANTOS, 2005, p.2).

A experiência dos estudantes com os líderes comunitários acontece, por exemplo, quando as ações extensionistas trazem esses parceiros para relatar suas experiências na Semana Integrada de Ensino, Pesquisa e Extensão; uma experiência plena de significado e relevância para todos os envolvidos.

É essa diversidade de pessoas e de formas de relacionamento com o conhecimento que faz a diferença na vida acadêmica, sendo que todos são imprescindíveis, tanto as ações como os sujeitos. Mas todos terão uma forma saudável de dialogicidade com o outro?

\section{INDISSOCIABILIDADE E INTERAÇÃO DIALÓGICA}

Um dos princípios da extensão universitária é a interação dialógica, entendida como o "estabelecimento e desenvolvimento de relação entre a universidade e os demais segmentos da sociedade por meio do diálogo e da troca de saberes" (UFPR, 2011). Morin (1991, p. 20) afirma que "a interação dialógica entre os sujeitos participantes de uma ação regenera o conhecimento compartilhado assim como regenera os próprios sujeitos envolvidos pelo conhecimento". Dessa forma, não há nada estagnado e estático, nem as ações nem os sujeitos, o tempo todo, tudo e todos estão se transformando e se alterando. Além disso, a "dialogicidade leva ao encontro de ideais diferentes, antagônicos e estabelece uma relação de conflito, onde os sujeitos passam a se questionar, a duvidar, a levantar novas possibilidades. Essa ruptura no conformismo rotineiro é o caminho para a construção da solução de problemas" (MORIN, 1991). A interação dialógica, assim, se torna imprescindível para a formação de cidadãos críticos e autônomos, sejam da comunidade universitária sejam dos grupos parceiros nas ações. Este também é o pensamento de Paulo Freire: "O pensar crítico implica o diálogo, que é, também, o único capaz de

REIMER, Marilene e ZAGONEL, Rosa M. A indissociabilidade consciente: uma reflexão sobre o cotidiano da docência. Extensão em Foco, Curitiba: Editora da UFPR, nr.9, jan/jun 2014, p.50-60. ISSN 2358-7180 
gerá-lo. Sem ele, não há comunicação e, sem esta, não há educação. A educação é diálogo" (FREIRE, 1997, p. 154).

Esta concepção deveria embasar as ações indissociáveis na universidade, qualquer que seja seu foco: o ensino, a pesquisa ou a extensão. Infelizmente, esta não é a regra, pois nas relações entre seres humanos existem inevitáveis conflitos e divergências de pensamentos e não é fácil a "ruptura no conformismo rotineiro". Para vivenciar esta concepção é necessário sair da zona de conforto, aventurar-se em terreno pouco conhecido.

A forma como os executores se referem aos parceiros das ações ajuda a esclarecer um pouco como eles entendem esta dialogicidade e como se dará a abordagem na execução. Nas ações extensionistas o outro pode ser chamado, entre outros, de público-alvo, comunidade, destinatário ou grupo parceiro.

Uma palavra muito utilizada é público-alvo. O próprio termo diz que é um grupo que será atingido, alvejado; não mostra relação nem parceria de forma aparente. Para o público-alvo, pode-se ministrar uma palestra ou um curso, realizar assistência à saúde, ou seja, difundir o conhecimento, devolver à sociedade o que foi investido em ensino, pesquisa e extensão na universidade.

Em outras ações o termo utilizado é comunidade, quase sempre com o sentido de população carente, moradora de áreas degradadas com quem a universidade realiza ações de empoderamento visando à melhoria das condições de vida e trabalho da população e o resgate do ambiente em que vive. Estas ações refletem o entendimento de extensão universitária voltada basicamente ao atendimento dos pobres e desfavorecidos e podem ou não se constituir dialógicas.

Quando o termo utilizado é destinatário, pensa-se logo em prestação de serviços com aporte de recursos financeiros, seja de empresas privadas seja de instituições públicas. A tendência da política do MEC para as IES está voltada para formas de atuação extensionista neste formato. Os futuros profissionais, atuais universitários, participam de ações fomentadas pelo governo federal, estadual ou municipal envolvendo-se com as comunidades do entorno. Maciel (2010, p. 17) afirma que

REIMER, Marilene e ZAGONEL, Rosa M. A indissociabilidade consciente: uma reflexão sobre o cotidiano da docência. Extensão em Foco, Curitiba: Editora da UFPR, nr.9, jan/jun 2014, p.50-60. ISSN 2358-7180 
se cada estudante dedicasse pelo menos um ano de seus estudos em atividades sociais, seria possível, por meio da extensão universitária, a cada ano, envolver mais de um milhão de estudantes em atividades socialmente engajadas que contribuiriam para a melhoria do Brasil. Tal contingente [...] resultaria em uma impressionante contribuição na oferta de serviços públicos (educação, saúde, moradia) nos municípios do interior do país, transformando a educação superior em um verdadeiro vetor de melhoria da qualidade de vida da população.

Essas ações são importantes para a formação acadêmica, profissional e cidadã dos estudantes e para a melhoria da qualidade de vida das comunidades participantes ou o crescimento das bases das comunidades ou dos grupos parceiros, pois o aporte de recursos financeiros possibilita intervenções concretas; mas por outro lado, a comunidade universitária pode se tornar ferramenta utilitária do sistema, reforçando a execução de políticas públicas e assumindo o papel de protagonista num enredo em que deveria ser coadjuvante. Corre-se o risco de uma "descaracterização do papel da universidade" (MICHELOTTO, 1999, p. 135) e da extensão, com utilização dos estudantes como mão de obra barata em ações desvinculadas de sua formação.

Quando o termo utilizado é grupo parceiro, podemos pensar em compartilhamento, parceria, troca, busca conjunta. Não é importante, aqui, o perfil da população parceira da ação: podem ser pessoas físicas, associações populares, ONGs, instituições públicas como secretarias municipais e estaduais, escolas, unidades de saúde, instituições privadas, etc. O que se pretende nesta ação é a construção de uma relação sólida, capaz de promover impacto em todos os envolvidos por meio de ações articuladas e duradouras, na busca e construção de soluções e socialização do conhecimento decorrente. O objetivo é o protagonismo e a autonomia para todos os participantes durante o tempo de execução das ações e para além delas. Neste tipo de ação ensino, pesquisa e extensão são indissociáveis.

Esta concepção se aproxima da educação preconizada por Paulo Freire, quando afirma que "o conhecimento não se estende do que se julga sabedor até aqueles que se julga não saberem; o conhecimento se constitui nas relações homem-mundo, relações de transformação, e se aperfeiçoa na problematização crítica destas relações." (FREIRE, 2006, p. 36).

REIMER, Marilene e ZAGONEL, Rosa M. A indissociabilidade consciente: uma reflexão sobre o cotidiano da docência. Extensão em Foco, Curitiba: Editora da UFPR, nr.9, jan/jun 2014, p.50-60. ISSN 2358-7180 


\section{CAMINHOS POSSÍVEIS DA INDISSOCIABILIDADE}

A indissociabilidade ensino-pesquisa-extensão ainda é um tema que carece de maior visibilidade. Na prática do dia a dia universitário, observam-se ações extensionistas indissociáveis do ensino e da pesquisa, imbricadas a ponto de não se distinguir onde inicia uma e termina outra. São ações que envolvem docentes, às vezes técnicos administrativos, alunos de graduação, de pós-graduação e parceiros externos amalgamados em atividades conjuntas e complementares. O conteúdo e a metodologia da ação estão de tal forma impregnados no fazer do coordenador que, nas palavras de uma professora pesquisadora e extensionista, ele se faz professor por meio dela e é ela que dá sentido a sua prática. Outros, não diretamente envolvidos, são beneficiados, quando o conteúdo desenvolvido pela e na ação se incorpora aos conteúdos de aulas e é socializado em debates e produtos. As dificuldades nesta ação surgem por conta das demandas administrativas, quando é necessário explicitar suas atividades separadamente para dar luz a somente uma das facetas envolvidas. Pode acontecer de a pesquisa ou o projeto de extensão parecerem órfãos e frágeis, arrancados do tronco que os alimenta, une e amarra.

Por outro lado, veem-se ações chamadas extensionistas, mas que tem como objeto de atuação o assistencialismo e/ou a prática do ensino em grupos parceiros, mas, paradoxalmente, sem parceria, sem pesquisa e sem extensão de fato. Estes, muitas vezes, respondem às demandas processuais administrativas de forma mais direta e objetiva, por não lidarem com a subjetividade e a incerteza do confronto com realidades distintas.

Apesar da diversidade de sujeitos, da forma como atuam na construção do conhecimento, e também por causa desta diversidade, a extensão, indissociada do ensino e da pesquisa, deveria fazer parte de todas as etapas da formação dos estudantes para que, ao se defrontarem com a prática profissional, possam ser flexíveis, dialógicos, articulados, críticos, inconformados e tenham como norte a busca da melhoria da qualidade de vida para si e para os outros. A indissociabilidade está presente no conhecimento

REIMER, Marilene e ZAGONEL, Rosa M. A indissociabilidade consciente: uma reflexão sobre o cotidiano da docência. Extensão em Foco, Curitiba: Editora da UFPR, nr.9, jan/jun 2014, p.50-60. ISSN 2358-7180 
produzido na sociedade ao longo do tempo e o conhecimento produzido e sistematizado na academia é fruto de ações de ensino, pesquisa e extensão; atuantes indissociáveis um do/no outro.

A extensão universitária, indissociada do ensino e da pesquisa, é única, é contato, é parceria, é confronto, é articulação, é angústia, é dúvida, é construir e reconstruir, é desistir e retornar, é mudar. É o eco do outro dentro de cada ação.

\section{REFERÊNCIAS}

BRASIL. Constituição da República Federativa do Brasil. 1988. Disponível em: <http://www.planalto.gov.br/ccivil_03/Constituicao/Constitui\%C3\%A7ao.htm>. Acesso em: 28/02/2012.

BRASIL. Lei n. 9394, de 20 de dezembro de 1996. Estabelece as diretrizes e bases da educação nacional. Curitiba: APP-Sindicato/Fórum Paranaense em defesa da Escola Pública, Gratuita e Universal, 1997.

FORPROEX, Fórum de Pró-Reitores de Extensão das Universidades Públicas Brasileiras. Indissociabilidade Ensino-pesquisa-extensão e a flexibilização curricular: uma visão da extensão. Porto Alegre: UFRGS, Brasília: MEC/SESu, 2006.

FREIRE, Paulo. Pedagogia da Autonomia: saberes necessários à prática educativa. São Paulo: Paz e Terra, 1996.

FREIRE, Paulo. Pedagogia da Autonomia: saberes necessários à prática educativa. 25a Edição. São Paulo: Paz e Terra, 2002

FREIRE, Paulo. Extensão ou Comunicação. 13. ed. São Paulo: Paz e Terra, 2006.

FREIRE, Paulo. Política e educação. São Paulo: Cortez, 1997.

MACIEL, Lucas Ramalho. Política Nacional de Extensão: perspectivas para a universidade brasileira. Revista Participação, Brasília: Universidade de Brasília, Ano 10, n. 18, dez. 2010.

MICHELOTTO, Regina M. Universidade Pública Brasileira: democratização pela extensão? Tese (Doutorado em Educação) - Centro de Educação e Ciências Humanas. Universidade Federal de São Carlos, São Carlos, 1999.

MORIN, Edgar. O método IV As ideias: a sua natureza, vida, habitat e organização. Publicações Europa - América, Portugal, 1991.

REIMER, Marilene e ZAGONEL, Rosa M. A indissociabilidade consciente: uma reflexão sobre o cotidiano da docência. Extensão em Foco, Curitiba: Editora da UFPR, nr.9, jan/jun 2014, p.50-60. ISSN 2358-7180 
NOGUEIRA, Maria das Dores Pimentel (Org.). Extensão universitária: diretrizes conceituais e políticas. Belo Horizonte: Fórum Nacional de Pró-Reitores de Extensão das Universidades Públicas, Universidade Federal de Minas Gerais, 2000.

ROBAYO, Carlos H. F. La extensión universitaria como fuente de transformación social e institucional. Congresso Ibero-americano de Extensão Universitária: Colômbia, 2007.

SANTOS, Boaventura de Souza. Repórter Social. 2005. Disponível em: $<$ http://www.boaventuradesousasantos.pt/documentos/universidade_mercantiliz acao_educacao.pdf>. Acesso em: 09/03/2012.

UFPR. Resolução no 72/11-CEPE. Dispõe sobre as Atividades de Extensão na Universidade Federal do Paraná. Disponível em: $<$ http://www.ufpr.br/soc/resolucoes.

php?conselho=\&item=ResoluçõesVigentes $>$. Acesso em: 22/02/2012. 